IdeAs

Idées d'Amériques

$7 \mid 2016$

Cinéma et histoire dans les Amériques

\title{
A representação do mal-estar da sociedade americana em Rocky e Os Embalos de Sábado à Noite
}

The representation of the malaise of American society in Rocky and Saturday Night Fever

La représentation du malaise de la société américaine dans Rocky et La Fièvre du Samedi Soir

\section{Sérgio Alpendre}

\section{OpenEdition}

Journals

Electronic version

URL: https://journals.openedition.org/ideas/1590

DOI: $10.4000 /$ ideas. 1590

ISSN: 1950-5701

\section{Publisher}

Institut des Amériques

Electronic reference

Sérgio Alpendre, "A representação do mal-estar da sociedade americana em Rocky e Os Embalos de Sábado à Noite", IdeAs [Online], 7| 2016, Online since 01 July 2016, connection on 18 October 2022. URL: http://journals.openedition.org/ideas/1590 ; DOI: https://doi.org/10.4000/ideas.1590

This text was automatically generated on 18 October 2022 .

\section{cc) (†)}

Creative Commons - Attribution-NonCommercial-NoDerivatives 4.0 International - CC BY-NC-ND 4.0

https://creativecommons.org/licenses/by-nc-nd/4.0/ 


\section{A representação do mal-estar da sociedade americana em Rocky e Os Embalos de Sábado à Noite}

The representation of the malaise of American society in Rocky and Saturday Night Fever

La représentation du malaise de la société américaine dans Rocky et La Fièvre du Samedi Soir

Sérgio Alpendre

\section{Introdução e contexto}

1 A intenção deste artigo é investigar o momento cinematográfico dos Estados-Unidos, entre 1975 e 1978, quando a sociedade passava por uma crise econômica e moral advinda de acontecimentos marcantes, e em que medida o mal-estar da época é sensível em dois filmes menos autorais ou incisivos: Rocky - Um Lutador (John G. Avildsen, 1976) e Os Embalos de Sábado à Noite (John Badham, 1977).

Rocky marca o início do estrelato de Sylvester Stallone, e foi vencedor do Oscar de melhor filme de 1976; Os Embalos de Sábado à Noite é um testemunho da disco, estilo musical mais influente da época ao lado do punk rock, e é o filme que confirmou John Travolta como um astro de primeira grandeza naquele momento. Os longas estão ligados pelo momento histórico, mas também porque o produtor de Embalos, Robert Stigwood, tentou, desde cedo, fazer uma versão disco para Rocky ${ }^{1}$.

3 Para seguirmos um caminho mais seguro, partiremos da ideia apresentada por Ismail Xavier na introdução de Sertão Mar, na qual o pesquisador analisa as obras iniciais de Glauber Rocha (Barravento e Deus e o Diabo na Terra do Sol) com o propósito de "identificar como, nos filmes analisados, as características de imagem e de som se põem como respostas a demandas que vêm da esfera do político e do social, e como também elementos de outra natureza entram no jogo que constitui a obra" (Xavier I., $2007: 15$ ). 
No primeiro parágrafo da introdução, ao comentar a tão falada estética da fome do cinema novo brasileiro, Xavier de certa forma ilumina o nosso caminho:

Da fome. A estética. A preposição "da", ao contrário da preposição "sobre", marca a diferença: a fome não se define como tema, objeto do qual se fala. Ela se instala na própria forma do dizer, na própria textura das obras (Xavier I., $2007: 13$ ).

Fredric Jameson chega à tese de que

toda obra de arte contemporânea - seja da alta cultura e do modernismo, ou da cultura de massa e comercial - contém como impulso adjacente, embora na forma inconsciente amiúde distorcida e recalcada, nosso imaginário mais profundo sobre a natureza da vida social, tanto no modo como a vivemos agora como naquele que sentimos em nosso íntimo - deveria ser (Jameson, 1979 : 34-35).

5 Ideia semelhante, que nos servirá igualmente, é a escrita por Kracauer. Segundo o pensador alemão,

O lugar que uma época ocupa no processo histórico pode ser determinado de modo muito mais pertinente a partir da análise de suas discretas manifestações de superfície do que dos juízos da época sobre si mesma. Estes, enquanto expressão de tendências do tempo, não representam um testemunho conclusivo para a constituição conjunta da época. Aquelas, em razão de sua natureza inconsciente, garantem um acesso imediato ao conteúdo fundamental do existente. Inversamente, ao seu conhecimento está ligada sua interpretação. O conteúdo fundamental de uma época e os seus impulsos desprezados se iluminam reciprocamente (Kracauer F., 2009 : 91).

6 O trecho acima diz mais respeito a um trabalho de historiador do que à análise de uma obra de arte, mas pensamos que pode nos servir também para analisar os filmes escolhidos, pois neles podemos encontrar essas "discretas manifestações de superfície" sobre as quais escreveu Kracauer, além de elementos escondidos que apenas uma visão detalhada poderia encontrar.

7 Rocky e Os Embalos de Sábado à Noite marcaram, de maneiras diferentes, uma época em que os parâmetros de sucesso encontravam-se em rápida mudança, e o estilo independente ganhava em paralelo uma face mais comercial (em relação à face mais experimental, de Jonas Mekas, Andy Warhol, Hollis Frampton, Robert Kramer entre outros). Os dois filmes (que não são bem independentes, mas tiveram orçamentos pequenos se comparados aos filmes característicos dos grandes estúdios) ${ }^{2}$ representam, como podemos concluir pelo desempenho de ambos nas bilheterias ${ }^{3}$, o que o público queria ver na época: histórias que vislumbravam uma esperança para aqueles tempos críticos e negativos.

Rocky - Um Lutador tem diversas imagens das ruas de Filadélfia, onde a história se passa. São ruas sujas, com mendigos e vagabundos agrupados em pleno dia. Além disso, há um sentimento de fracasso profissional que perpassa o filme, com personagens desiludidos, mutilados espiritualmente por experiências malogradas do passado. A redenção final do boxeador vivido por Stallone não esconde a melancolia evidente nas cenas em que ele tenta recuperar a velha forma, ou nos momentos em que é humilhado e ofendido.

Os Embalos de Sábado à Noite é o retrato mais famoso da era disco, e também um dos mais realistas, ao que nos parece. Filmes como Studio 54 (Mark Christopher, 1998) e Os Últimos Dias da Disco (Whit Stillman, 1998), e até mesmo Até Que Enfim é Sexta-Feira (Robert Klane, 1978), que é praticamente contemporâneo a Embalos, tendo estreado poucos meses depois, retratam esse estilo musical e comportamental como um momento de felicidade generalizada e inconsequente, quando a sociedade americana mergulhou 
com tudo nas discotecas e suas noitadas regadas a bebida, sexo e cocaína. Interpretar dessa forma é enxergar apenas a superfície das coisas. O filme de John Badham nos ajuda a perceber que a música disco era na verdade um escape da realidade dura das ruas. Como nos musicais da Grande Depressão, nos quais a crise econômica era geralmente tematizada de maneira explícita, o mal-estar está presente em quase toda a duração do filme que serviu de catapulta para o fenômeno da música disco, seja no entorno que cerceia a vida de Tony Manero, o personagem de John Travolta, seja nas dificuldades por que passam diversos personagens do filme.

10 Esses dois filmes indicam que, para que o mal-estar fosse sentido, não era necessário mostrar soldados violentos ou mutilados, como em A Outra Face da Violência (John Flynn, 1977), Amargo Regresso (Hal Ashby, 1978) e O Franco Atirador (Michael Cimino, 1978), ou investigações usando escutas eletrônicas, como no sublime A Conversação (Francis Ford Coppola, 1974), ou ainda o sofrimento de protagonistas que se encaixavam em alguma das chamadas minorias (negros, homossexuais, imigrantes, mulheres), como o casal homossexual vivido por Al Pacino e Jon Casale em Um Dia de Cão (Sidney Lumet, 1975). É na direção de explorar elementos menos óbvios de representação desse contexto que este artigo se apresenta.

11 Como vimos anteriormente, além da Guerra do Vietnã, um conflito complexo e extremamente duro, com batalhas em densas florestas asiáticas, em que os EUA foram política e moralmente derrotados, outros acontecimentos foram determinantes para a prevalência de um mal-estar na sociedade americana, o que foi crucial para o delineamento de opções estéticas e temáticas nas produções cinematográficas dos anos 1970, especialmente em algumas realizadas a partir de 1975. Houve, por exemplo, a crise do petróleo, em outubro de 1973, quando a OPEP (Organização dos Países Exportadores de Petróleo) iniciou um embargo como represália ao apoio dado pelos Estados Unidos a Israel na Guerra do Yom Kippur. Isto causou um grande impacto na economia norte-americana, e uma recessão que, segundo o historiador Sean Purdy, "seria o primeiro de uma série de choques econômicos periódicos que continuaria até o século XXI" (Purdy S., 2007 : 238). Esse choque fez com que o governo adotasse posturas e medidas de ajuda social insuficientes para remediar o problema. Um escândalo político viria se somar ao panorama no ano seguinte, causando a renúncia do presidente Richard Nixon (1969-1974). Tal escândalo, que ficaria conhecido como Watergate (e que se iniciou, ainda tímido, em 1972), aprofundaria a crise moral em que mergulhava a sociedade americana, influenciando também as produções artísticas do período. Além disso, havia as reivindicações das chamadas minorias por igualdades sociais e por reconhecimento de seus direitos, que começaram a gerar insatisfação por parte das porções conservadoras da sociedade americana, especialmente da ascendente direita cristã (que se tornaria extremamente forte nos anos 1980). Essas reivindicações, bem como a reação a elas ou a dificuldade em atendê-las (e entendê-las) plenamente, ajudariam a estabelecer o tom crítico e amargo adotado por boa parte dos filmes da época. Era um momento em que o cinema, segundo Peter Lev, tematizava a morte dos anos 1960, das utopias e esperanças daquela década:

A "morte dos anos 1960" (sixties) tornou-se um tema proeminente em filmes americanos em 1974-1976, quando os catastróficos eventos de Watergate e a crise do petróleo, assim como a aparente falta de mudança social nos Estados Unidos sugeria que o momento de otimismo social estava realmente acabado. Vários filmes - Chinatown, Nashville, A Trama, Um Lance no Escuro, Shampoo, Um Estranho no Ninho descreviam a perda de idealismo e uma onipresente sensação de corrupção moral e 
política. Os anos 1960 foram lamentados em uma série de filmes memoráveis. A tendência continuou, com filmes do fim dos anos 1970 e entrando na década de 1980, documentando e criticando a contracultura dos anos 1960 (Lev, P., 2000 : 61).

12 Eis o contexto em que surgiram os filmes de Avildsen e Badham. Após uma série de acontecimentos que começavam a enterrar as utopias da contracultura já nos anos 1960, reverberando nos anos 1970 e influenciando continuamente o cinema produzido na época.

13 Rocky e Os Embalos de Sábado à Noite marcam, cada qual, um ano específico. 1976 e 1977: estamos portanto num biênio crucial do que o crítico e historiador francês JeanBaptiste Thoret chamou de "momento do desencanto (1972-1979)", em que

Os cineastas são os mesmos, os atores também, mas entre Voar é com os Pássaros [1970] e Nashville [1975] (Robert Altman), entre Meu Ódio Será Sua Herança [1969] e Elite de Assassinos [1975] (Sam Peckinpah), entre O Pequeno Grande Homem [1970] e Um Lance no Escuro [1975] (Arthur Penn), entre Ensina-me a Viver [1971] e Shampoo [1975] (Hal Ashby), algo se quebrou. Os filmes ainda são muito belos, talvez ainda mais belos, mas o olhar em relação ao mundo mudou. Após a explosão, o arrefecimento. O sufocamento dos movimentos de contestação e da contracultura, o fim da Guerra do Vietnã e do alistamento, os escândalos políticos e a recessão econômica mergulharam a América em um período de dúvida e recuo (Thoret, JB., 2009: 33, nossa tradução).

14 Dentro desse período de arrefecimento, ou de relaxamento, no qual identificamos o mal-estar com o qual trabalhamos neste artigo, a poderosa engrenagem de Hollywood encontrou, no sucesso de Tubarão (Steven Spielberg, 1975) Rocky e Guerra nas Estrelas (George Lucas, 1977), principalmente, o incentivo primordial para fazer com que os interesses financeiros voltassem a dominar os meios de produção, colocando em plano secundário os sonhos autorais e contestatórios dos diretores da Nova Hollywood. Haveria cada vez menos espaço para o risco e a invenção.

150 momento histórico da segunda metade dos anos 1970 já possibilita entrevermos a reviravolta comercial (do blockbuster) que faria de Hollywood novamente uma potência econômica e imperialista. O século XXI e sua pobreza estética são um belo exemplo de onde tudo foi dar. A arte e o desejo de compreender o mundo hoje fazem parte da minúscula exceção em Hollywood, e cineastas com mais personalidade são obrigados a buscar recursos alhures. Contudo, se o período em questão, a segunda metade dos anos 1970, pode ser considerado o início de uma infantilização irreversível do cinema hollywoodiano, ainda podemos notar, em algumas produções que vão daquele momento até meados dos anos 1990, um resquício da crítica encontrada nos filmes do auge da Nova Hollywood, ou ao menos um retrato do mal-estar pelo qual a sociedade americana passava na época. É o caso, acreditamos, de Rocky - Um Lutador e Os Embalos de Sábado à Noite.

\section{Rocky, o azarão de Filadélfia}

16 Rocky - Um Lutador, de John G. Avildsen, com produção de Robert Chartoff e Irwin Winkler para distribuição da United Artists, ganhou o prêmio principal da academia num ano em que um dos indicados era Taxi Driver (Martin Scorsese, 1976), filme de maior prestígio, que já havia vencido a Palma de Ouro em Cannes e que mostrava um retrato mais direto da situação econômica e do trauma no Vietnã e Watergate. Os outros indicados eram Esta Terra é Minha Terra (Hal Ashby, 1976), um filme histórico, 
além de Todos os Homens do Presidente (Alan J. Pakula, 1976) e Rede de Intrigas (Sidney Lumet, 1976), filmes que esmiúçam o jornalismo americano (impresso no primeiro caso, televisivo no segundo).

17 A preferência por um retrato que terminasse de maneira mais positiva é sintomática. A indústria cinematográfica americana sempre preferiu os heróis que lutam contra as dificuldades e vencem na vida aos heróis que desenvolvem um processo de catarse pela violência, sem que estivesse envolvido no processo algo edificante, que reestabelecesse uma moral ou uma sensação de oportunidade (no caso de Rocky, a da segunda chance). Ainda que Taxi Driver termine de maneira ligeiramente positiva (muitos poderiam dizer, com razão, ironicamente positiva), o clima de desesperança é mais forte e evidente.

18 Rocky foi lançado em dezembro de 1976, no crepúsculo de um ano em que os americanos comemoravam o bicentenário da independência dos Estados Unidos da América. Na história do filme que se tornou a maior bilheteria do ano e o grande vencedor dos Oscars concedidos no ano seguinte, estamos inicialmente em novembro de 1975, com os preparativos para as comemorações dos 200 anos da chamada América. Destas comemorações, dentro do filme, faz parte a luta contra o campeão mundial para a qual o herói treina incessantemente.

19 Os festejos, fora do filme, mas incidindo de forma indireta na indústria do cinema, intensificaram-se nos dias próximos ao 4 de julho que marca a data da assinatura da Independência, e caíram como uma luva dentro de um processo de tentativa de recuperação econômica e moral de uma sociedade ainda ferida pelos traumas recentes.

Gordon Arnold resumiu bem a situação em que tais festejos se inseriam:

Durante o verão de 1976, espectadores da televisão foram apresentados com muitas notícias e reportagens especiais sobre o bicentenário dos Estados Unidos. A ocasião do aniversário de 200 anos estabeleceu um palco onde toda a História dos EUA podia ser mostrada. Dirigir a atenção à história americana como um todo não desmanchava a incômoda percepção do fracasso nacional no Vietnã. Ao estender a reconsideração de importantes eventos de um passado distante, contudo, desenvolveu-se um processo no qual a Guerra do Vietnã pudesse ser vista apenas como um único episódio dentro da grande narrativa (Arnold G., 2006: 40, nossa tradução).

21 Frank P. Tomasulo, que elaborou para o livro American cinema of the 1970s um texto que fala exclusivamente do cenário americano (cinematográfico, mas não só) de 1976, conta, de forma análoga à de Arnold, o cenário político da ocasião:

Em seu ano do bicentenário, os Estados Unidos estavam arruinados pela desilusão e desconfiança do governo. O escândalo Watergate e a evacuação do Vietnã ainda estavam frescos na mente de todos. Forçado a lidar com esses eventos traumáticos, combinados com a letargia da economia ( $8,5 \%$ de desempregados), com a escassez de energia e com altas de preço de 5 a $10 \%$ na OPEP, além do declínio do dólar americano na bolsa internacional, a psique americana sofria com um clima de desespero e, seguindo uma célebre frase do novo governador da Califórnia Jerry Brown no ano anterior, "expectativas reduzidas" (Tomasulo F., 2007: 157, nossa tradução).

22 Após anos de dominação ${ }^{4}$ de filmes críticos, politizados e extremamente negativos em relação ao American way of life, 1976 marcou o fortalecimento de uma série de feel good movies, com histórias de superação e otimismo, dos quais o mais emblemático, pelo imenso e inesperado sucesso, é justamente Rocky. 
23 Para mostrar uma história de superação, contudo, é necessário mostrar também o que se está superando. Rocky se insere, dessa maneira, num imenso grupo de filmes que capta um mal-estar na sociedade sem necessariamente se contaminar por ele, terminando em chave positiva, como nos filmes de Frank Capra dos anos 1930 (durante o New Deal de Roosevelt). A crise está lá estampada, mas a conquista pessoal de um herói da classe trabalhadora acaba suplantando-a. É a melhor maneira de se lidar com as dificuldades: insuflar-se de um clima em que a recuperação, a segunda chance e a oportunidade são fatores atingíveis para todos em meio às dificuldades de um período difícil da história.

24 Rocky mostra diversas imagens das ruas de Filadélfia, onde a história se passa. São ruas sujas, com desocupados e vagabundos agrupados em pleno dia (não vemos violência no filme além da que acontece nos ringues, mas Rocky menciona o perigo que existe para uma mulher andar por ali). Há um sentimento de fracasso profissional que perpassa toda a primeira metade do filme, com personagens desiludidos, mutilados espiritualmente por experiências malogradas do passado. A redenção final do boxeador vivido por Stallone, que consegue aguentar até o fim da luta sem ser derrubado pelo grande campeão, não esconde a melancolia evidente nas cenas em que ele tenta recuperar a velha forma, ou nos momentos em que defende um emprego mais simplório e condenável do que lutar boxe profissionalmente (o de coletar dívidas para um agiota local), ou ainda quando testemunha as brigas de seu amigo com a irmã.

25 O ginásio onde os boxeadores do bairro treinam sob o olhar de um velho instrutor transpira decadência. o lixo parece se espalhar por todos os lados da cidade (refletindo o estado de desânimo moral após Vietnã e Watergate), assim como os desocupados (lembrando da alta taxa de desemprego que a economia americana apresentava então). A melancolia está em cena, seja na escuridão das redondezas, no trem que passa encobrindo a cantoria dos desocupados (que cantam para espantar o frio e a infelicidade), nos subempregos dos habitantes, nos devedores que mal têm como se sustentar mas precisam pagar suas dívidas, ou no frigorífico em que o melhor amigo de Rocky trabalha (numa Filadélfia gelada, entrando no inverno, esse homem é obrigado a passar parte de seus dias dentro de um frigorífico).

26 Filadélfia foi a cidade onde se reuniu o congresso das colônias americanas que decidiram pela Declaração de Independência, assinada em 4 de julho de 1776. É, portanto, o lugar ideal para se narrar uma história de superação que é lançada no circuito comercial americano no último mês do ano em que o país comemora seu bicentenário.

27 Podemos dividir o filme em duas partes. A primeira mostra o lutador, nos seus trinta anos, fracassado, que parece ter jogado fora sua única oportunidade de ser alguém. Ao ser escolhido para lutar contra o campeão dos pesos-pesados, tem uma improvável segunda chance. Ele aceita, começa a treinar, mas não acredita no seu potencial. Ao mesmo tempo, envolve-se com a irmã do amigo Paulie, uma moça muito tímida que trabalha numa pet shop. Num primeiro momento, são várias as cenas do filme que refletem o mal-estar da sociedade na época: a crise econômica (são muitos os personagens que vivem de subempregos, e o número de desocupados nas ruas é grande), o desgaste moral pela derrota no Vietnã e pela vergonha de Watergate (algo mais subjetivo, que chama nossa atenção nas cenas que refletem a solidão dos personagens, mas também na timidez excessiva, envergonhada, de Adrian, ou no aspecto francamente decadente de Paulie, um beberrão ainda mais incapaz do que 
Rocky), o cansaço da maioria WASP - sigla em inglês para "branco, anglo-saxão e protestante" - com as reivindicações das chamadas minorias e suas conquistas (perceptível sobretudo na presença de boxeadores negros dentro do ginásio, mas também na configuração da equipe do grande campeão Apollo (reed).

$\mathrm{Na}$ segunda parte, quando Rocky percebe que deve treinar muito para não passar vexame, temos a fase "getting strong now", do treinamento. Rocky aos poucos vai ganhando velocidade, força, agilidade, subindo rapidamente as escadarias de um museu como se estivesse conquistando o mundo, tendo a música disco-triunfalista de Bill Conti ao fundo. É como se a primeira parte fosse o cinema americano dos anos anteriores, um cinema do desemprego, da crise econômica e moral, do retorno dos soldados de uma guerra fracassada, do mal-estar; e a segunda representasse o cinema que se inauguraria com o bicentenário, de afirmação, otimismo, um retorno à crença do sonho americano (the american "creed").

\section{New York, falência moral: Os Embalos de Sábado à Noite}

29 Além de ser um estilo musical marcado pela batida dançante e por melodias festivas, a disco music é um estado de espírito circunscrito a uma época específica, cujo auge coincide, nos Estados Unidos, onde surgiu (primeiro em Nova York, indo depois para todo o país), com os anos em que o democrata Jimmy Carter foi presidente. A disco está presente em diversos filmes americanos cujas histórias se ambientam parcial ou integralmente nesse período (1977-1980). o primeiro grande sucesso a explorar o estilo foi justamente Os Embalos de Sábado à Noite, produzido pela RSO de Robert Stigwood, o nome por trás dos Bee Gees, e distribuido pela Paramount.

Mas se Rocky - Um Lutador, de John G. Avildsen, mostrou, no final de 1976, a superação de um mal-estar e a confirmação da narrativa americana, ressignificando, com isso, o cinema hollywoodiano como o escape necessário a um público já muito machucado pela realidade, Os Embalos de Sábado à Noite, concebido por seu produtor como uma versão musical de Rocky (o que podemos confirmar pela análise de sua estrutura e de elementos da narrativa), sabotava de certo modo a adesão automática da Hollywood de então aos feel good movies (adesão que o Oscar de melhor filme dado a Rocky anunciava) e o retorno à fábrica dos sonhos da Hollywood de outrora. Sabotava por dois motivos: a) não era bem um feel good movie afinal, pois debaixo da música e da dança existia todo um contexto social, moral e econômico que insistia em aparecer; b) fez grande sucesso a despeito de seu teor adulto e do clima geral pesado, mostrando que ainda era possível, num contexto de preocupação com as bilheterias, ser crítico e questionador, desde que esses elementos viessem em embalagens mais palatáveis (e contrabalançadas com sinais de alegria e esperança). De fato, este veículo para John Travolta e para a música disco dos Bee Gees era bem mais crítico, realista e negativo, no tom geral, do que o ganhador do Oscar de melhor filme de 1976. E principalmente porque, ao contrário de Rocky, em Os Embalos de Sábado à Noite a trama se tornava mais "barra pesada" no final, com o inferno moral em que se encontrava o protagonista tornando-se mais evidente.

31 Quando Os Embalos de Sábado à Noite estreou, sua trilha sonora, em boa parte composta $\mathrm{e}$ executada pelos Bee Gees, já era um estouro de vendas, catapultando o filme para o topo da bilheteria. Trata-se de um drama em que a dança e a música entram como 
escape de um mundo pesado demais para ser suportado e compreendido por um jovem de 19 anos (a idade do protagonista Tony Manero). Vemos, inicialmente, Tony andando numa rua do Brooklyn, gingando ao som dos Bee Gees. Ao chegar à loja de tintas onde trabalha, Tony enfrenta a dura realidade daqueles que batalham por dinheiro para o fim de semana. Em casa, depois de um dia de trabalho, a dureza persiste. Seu pai está desempregado e a mãe é estritamente católica, de um modo que o irrita. Para completar, ela prefere sensivelmente o irmão mais velho de Tony, que é padre. Tony só se sente à vontade na pista de dança da discoteca de seu bairro, onde encontra amigos, garotas que o veneram, e onde se apaixona por uma dançarina talentosa que não corresponde a esse seu sentimento. Ela só quer saber de gente descolada de Manhattan. Mesmo assim, ela aceita fazer dupla com ele em um concurso de dança. Eles passam a ensaiar, e ela resiste como pode às investidas do garanhão. Aos poucos, Tony vai percebendo que aquele mundo, aquele ambiente em que é rei, está apodrecido, mergulhado em preconceitos arcáicos e num sexismo intolerável. Sente-se parte disso e faz o possível para se afastar desse mundo. Torna-se, a exemplo da moça pelo qual se apaixonou, um candidato a alpinista social. Pensa, como ela, que a solução está em Manhattan, do outro lado da ponte do Brooklyn que vemos no primeiro plano do filme.

O mal-estar da sociedade americana na segunda metade dos anos 1970, como já vimos, estava presente também nesses divertimentos à primeira vista inconsequentes. É algo que observamos, por exemplo, em qualquer cena em que o personagem de John Travolta está com sua família, ou nos momentos finais, quando sentimos um irreversível desequilíbrio na relação dele com os amigos. Numa primeira impressão, Os Embalos de Sábado à Noite é unicamente o registro cinematográfico da era disco enquanto esta se encontrava no auge. Como é característico do gênero, um filme de celebração da dança e do corpo, de sublimação pela música. Mas existe uma série de questionamentos, geralmente centrados no personagem de John Travolta, sobre a situação americana (moral, econômica, social) da época. A conclusão, a respeito do surpreendente sucesso de Rocky (que, contudo, foi um sucesso menor que o de Embalos), de que o público estava cansado de filmes críticos em relação à sociedade e ao país, não pode fazer com que fechemos os olhos para as possibilidades de leituras questionadoras que alguns filmes comerciais, insuspeitos numa primeira impressão de oferecer mais do que aparentam, revelam em suas entrelinhas, e muitas vezes mesmo numa primeira camada. Vejamos como isso se dá nos maiores sucessos do ano. Guerra nas Estrelas (George Lucas, 1977), por exemplo, pode ser interpretado como uma fábula antiimperialista, se pensarmos no poderio econômico do império comandado por Darth Vader oprimindo as nações que vivem em planetas desérticos (ecos da então recente crise do petróleo e do estremecimento dos EUA com os países árabes) ${ }^{7}$. O protagonista de Contatos Imediatos do $3^{\circ}$ Grau (Steven Spielberg, 1977), interpretado por Richard Dreyfuss (que no mesmo ano atuou no sucesso A Garota do Adeus, de Herbert Ross), abandona a esposa e três filhos para ter uma nova experiência com os extraterrestres, ressaltando a irresponsabilidade e a alienação de uma geração e assinalando uma obsessão spielberguiana que seria retomada em muitos de seus filmes: a ausência do pai. Fora que há uma sensação de imperfeição dominante na Terra, e de se aprender como viver melhor com os extraterrestres. Isso para ficarmos nos dois maiores sucessos comerciais do ano. O primeiro deles, Guerra nas Estrelas, ultrapassando Tubarão (Steven Spielberg, 1975) e "tornando-se o filme mais rentável de todos os tempos" (Biskind P., 2009: 356). 
Claro que o terceiro maior sucesso de 1977, justamente Os Embalos de Sábado à Noite, teria também esses elementos, para lembrar aos espectadores que não havia um mar de rosas fora das salas de cinema. Mesmo a diversão, durante o domínio da Nova Hollywood, poderia conter alguma dose de questionamento e negatividade. $\mathrm{O}$ pai de Tony Manero (personagem principal de Embalos) não se torna ausente como o de Contatos Imediatos do $3^{\circ} \mathrm{Grau}$, mas está desempregado há um bom tempo, o que obriga a mãe a fazer um grande esforço para salvar as economias familiares. O clima na mesa de jantar, por esse motivo, nunca é dos mais agradáveis. E este é apenas um dos sinais da realidade que invade esse musical dos novos tempos, de crise econômica e moral da sociedade americana ${ }^{8}$, marcado pelas experiências estéticas das décadas anteriores (câmera na mão, cenas de rua, ambiguidade na história e nos personagens), pela maneira de filmar estabelecida pelos jovens diretores da Nova Hollywood.

Os Embalos de Sábado à Noite foi na época um veículo para o então candidato a astro John Travolta e uma espécie de registro da era disco, onda musical e comportamental marcada por um visual alegre (ternos brancos ou de cores fortes, adereços brilhantes, camisas de golas enormes e sapatos plataforma) e por uma música simples e dançante. Apesar desse enganoso invólucro, e do incrível sucesso comercial que o filme obteve, percebemos, em suas engrenagens, sinais evidentes do mal-estar que então perpassava a consciência americana. Os Embalos de Sábado à Noite sucedeu Rocky - Um Lutador na missão de oferecer um horizonte mais positivo ao público, cansado da crítica e da negatividade vinda dos diretores da chamada Nova Hollywood. Seu lado tenebroso era difícil de se esconder, mas o apelo da dança, a trilha já famosa dos Bee Gees e o carisma de John Travolta carregaram o filme ao triunfo. Além disso, há um lado para cima que é forte no filme. Se compararmos o final de Shampoo, um dos maiores sucessos de bilheteria de 1975, realizado por Hal Ashby (diretor associado à Nova Hollywood), com o final de Os Embalos de Sábado à Noite, notamos que a desilusão foi substituída pela esperança, sem que o final do último seja necessariamente positivo. Em Shampoo, o protagonista termina sozinho, vendo sua amada partir com outro homem, mais velho e melhor estabelecido profissionalmente, do alto de um penhasco (o retrato do isolamento e do desencanto). Ou seja, a vida mais libertária típica dos anos 1960 (lembremos que a história de Shampoo se passa em 1969) é preterida no filme em favor de uma vida mais segura ao lado de um homem maduro, valores que voltariam a predominar, aos poucos, durante os anos 1970, e principalmente nos anos 1980. Embalos, por outro lado, termina com um abraço de amizade entre o protagonista e a mulher pela qual ele se apaixonou. Não é, evidentemente, um filme todo "para cima", nem mesmo um filme em que predomine esse lado (que é forte, conforme mencionado acima, mas não dominante). A época em que foi realizado parecia não permitir tamanho otimismo, a não ser em filmes para um público juvenil, o que não é bem o caso - acabaria se tornando um filme para esse público, para sorte dos produtores e apesar das intenções do diretor John Badham de fazer um filme mais sério, por causa do apelo da música disco entre os jovens.

Pensando na importância do filme como documento de época, e tomando como base sua repercussão comercial, é importante lembrar que muitos de seus aspectos adultos (linguagem vulgar, nudez, cenas de estupro, suicídio) impediram que fosse um sucesso ainda maior. Em um capítulo de Lost Illusions que versa sobre os blockbusters, David A. Cook escreveu, seguindo caminho aberto por J. Hoberman, que Os Embalos de Sábado à Noite "foi também o primeiro filme para a juventude pós-anos 1960 com uma história 
contemporânea e atraiu um novo mercado jovem" (Cook D., 2002: 55, nossa tradução). Mais adiante, Cook relata que um estudo feito em 1977 pela MPAA (Motion Picture Association of America) indicava que

$57 \%$ dos espectadores de cinema do país tinham de 12 a 24 anos. o que significa que uma grande porção da audiência em potencial para Os Embalos de Sábado à Noite foi excluída devido às fortes cenas de sexo e à linguagem chula (Cook D., 2002: 55, nossa tradução). distribuição da Paramount, fez um sucesso ainda maior sendo bem mais adolescente (e inconsequente), e por esse motivo Embalos teve um relançamento quase dois anos depois, com todo o conteúdo adulto extraído do filme. Tirando as cenas adultas da versão R-Rated de Os Embalos de Sábado à Noite para tal relançamento, a Paramount conseguiu anular boa parte do interesse do filme, restando apenas a música e a dança e o carisma de John Travolta. Seria um prenúncio da Hollywood infantilizada de hoje?

\section{BIBLIOGRAPHY}

Arnold, Gordon, The afterlife of America's war in Vietnam: changing visions in politics and on screen, Jefferson, NC, McFarland \& Company, 2006.

Biskind, Peter, Como a geração sexo, drogas e rock and roll salvou Hollywood, Rio de Janeiro, Intrínseca, 2009.

Cook, David A., Lost Illusions: American Cinema in the Shadow of Watergate and Vietnam, 1970-1979, Berkeley, University of California Press, 2002.

Coursodon, Jean Pierre e Tavernier, Bertrand, 50 ans de cinéma américain, Paris, Nathan, 1995. Jameson, Fredric, Marcas do Visível, Rio de Janeiro, Graal, 1995.

Kracauer, Sigmund, O ornamento da massa, São Paulo, Cosac \& Naify, 2009.

Lev, Peter, American Films in the '70s - Conflicting Visions, Austin, University of Texas Press, 2000.

Purdy, Sean, “Rupturas do Consenso: 1960-1980”, in Leandro Karnal (dir..), História dos Estados Unidos: das origens ao século XXI, São Paulo, Editora Contexto, 2007.

Schatz, Thomas, Hollywood Genres, New York, McGraw Hill, 1981.

Thoret, Jean-Baptiste, Le cinéma américain des années 70, Paris, Cahiers du Cinéma, 2009.

Tomasulo, Frank, “1976: Movies and Cultural Contradictions”, in Lester Friedman (dir.), American cinema of the 1970s: themes and variations, New Brunswick, NJ, Rutgers University Press, 2007, 157-204.

Xavier, Ismail, Sertão Mar, São Paulo, Cosac Naify, 2007. 


\section{NOTES}

1. Segundo Jean Pierre Coursodon e Bertrand Tavernier: “o conceito do filme [Os Embalos...] é sem dúvida o resultado de um lampejo de gênio do produtor Robert Stigwood que, ao ver a receita de Rocky nas bilheterias, teve a ideia de fazer uma versão disco. Bastava substituir o boxe pela dança e o ringue pelo baile de sábado à noite. Norman Wexler [roteirista do filme] tece um plágio astucioso do modelo, transpondo ou parafraseando a maior parte das etapas dessa história de sucesso arquetípica. Bastava encontrar um ítalo-americano igualmente plebeu e inculto, mas carismático para o exercício de um talento físico (o gestual da dança disco substitui aquele do boxe)." (Coursodon JP., Tavernier B., 1995 : p. 292, nossa tradução).

2. Segundo o site imdb.com, Rocky teve orçamento de aproximadamente 1 milhão de dólares. Os Embalos de Sábado à Noite custou 3 milhões. É praticamente o triplo de Rocky, mas se comparado ao orçamento das duas maiores bilheterias de 1977 (Os Embalos seria a terceira maior bilheteria), esse valor é considerado baixo: Contatos Imediatos do $3^{\circ}$ Grau custou 20 milhões, aproximadamente, enquanto Star Wars, a maior renda do ano, custou 11 milhões (página consultada em 20 de junho de 2016).

3. Rocky foi o filme mais visto de 1976, e arrecadou 56,5 milhões de dólares enquanto esteve em cartaz nos Estados Unidos. Os Embalos de Sábado à Noite, por sua vez, arrecadou 74,1 milhões, e ficou em 3임 lugar (Cook D., 2002: 500-501).

4. Alguns autores questionam essa dominação, notadamente David Bordwell. Penso, contudo, que ela se dá sobretudo se forem considerados os filmes mais falados e elogiados do período.

5. Um outro momento de crítica profunda ao american way of life pode ser observado no ciclo de melodramas familiares dos anos 1950, sobretudo em filmes de Douglas Sirk e Vincente Minnelli (Schatz T., 1981). Outros momentos dessa crítica podem ser apontados dentro da História do Cinema Americano, mas o ciclo de melodramas, bem como o período da Nova Hollywood, nos parecem os mais incisivos.

6. No ápice da música tema, composta por Bill Conti, ouvimos um coro feminino cantando "getting strong now", coincidindo com a parte final do clipe em que Rocky vai aperfeiçoando-se nos treinos.

7. A analogia de Peter Biskind é um pouco diferente e bem interessante; é baseada nas declarações de Lucas de que o imperador do mal seria o presidente Nixon: "o vasto e poderoso Império só pode ser os Estados Unidos (mais especificamente Hollywood), e o bando maltrapilho de rebeldes com suas armas improvisadas, feitas de cacos, elásticos e goma de mascar, o vietcongue (ou os moleques da Nova Hollywood)." (Biskind P., 2009: 359).

8. Podemos traçar um paralelo com o momento de frutificação do gênero musical, no início dos anos 1930, quando a crise econômica era ainda maior, mas respirava-se um grande esforço político para a ultrapassagem da crise durante o New Deal de Roosevelt. Os musicais de então eram delirantes, alegres, esteticamente ousados, mas existia constantemente uma preocupação em situar o filme dentro dos problemas da época. Os produtores de espetáculo, por exemplo, viam-se não raro sem verba para realizar seus shows, por causa da crise econômica e do recuo de possíveis patrocinadores. À época, estava na moda o backstage musical, ou seja, musicais em que os números apareciam diegeticamente, como se fossem parte de um ensaio ou do show propriamente dito. 


\section{ABSTRACTS}

In this article we seek to investigate to what extent the malaise of American society between 1975 and 1978, caused by a series of events of the seventies (end of the Vietnam War, protest movements of social minorities, the OPEC crisis and Watergate, among others), was represented in commercial films made in Hollywood without auteurist ambitions. The films analyzed in this piece are Rocky (John G. Avildsen, 1976) and Saturday Night Fever (John Badham, 1977).

Neste trabalho investigamos em que medida o mal-estar da sociedade americana, entre 1975 e 1978, causado por uma série de acontecimentos dos anos 1970 (fim da Guerra do Vietnã, reivindicações das chamadas minorias sociais, crise da OPEP e Watergate, entre outros), foi representado em filmes comerciais feitos dentro de Hollywood e sem maiores ambições autorais. Os filmes analisados neste trabalho são: Rocky - Um Lutador (John G. Avildsen, 1976) e Os Embalos de Sábado à Noite (John Badham, 1977).

Dans cet article, nous examinons dans quelle mesure le malaise de la société américaine, entre 1975 et 1978, provoqué par une série d'événements dans les années 1970 (fin de la guerre du Vietnam, revendications des minorités sociales, crise de l'OPEP et Watergate, entre autres), a été représenté dans les films commerciaux, réalisés à Hollywood et sans grandes ambitions. Les films analysés sont Rocky (John G. Avildsen, 1976) et La Fièvre du Samedi Soir (John Badham, 1977).

\section{INDEX}

Mots-clés: histoire, cinéma américain, Hollywood, malaise, années 1970, Stallone, Travolta Palavras-chave: história, cinema americano, mal-estar, anos 1970, Stallone, Travolta, Hollywood Keywords: history, American cinema, Hollywood, malaise, '70s, Stallone, Travolta

\section{AUTHOR}

\section{SÉRGIO ALPENDRE}

Sérgio Eduardo Alpendre de Oliveira (Sérgio Alpendre) é Crítico de cinema, pesquisador e professor. É doutorando em Cinema pela Universidade Anhembi-Morumbi e Mestre em Meios e Processos Audiovisuais pela ECA-USP.

Av. Cons. Rodrigues Alves, 315/33

Vila Mariana - São Paulo/SP/Brasil

CEP: 04014-011

sealpendre@gmail.com 